\title{
How good is general practice developmental screening?
}

\author{
John Dearlove, David Kearney
}

\begin{abstract}
All developmental screening in Somerset is performed by general practitioners and health visitors. A retrospective review of a cohort of 15047 year old children living in semirural Somerset found that the development assessment by a health visitor at age $31 / 2$ years had a sensitivity of $45 \%$ for identifying the 103 children with special educational needs, whereas the sensitivity of the preschool examination by a general practitioner was $56 \%$. There was no relation between results of preschool developmental assessment and later reading ability. Of the 23 children in special schools, 22 had been identified independently of the developmental screening programme before starting school. Intervention was started at a mean age of 1 year 5 months (range 2 months to 3 years) for children with severe learning difficulties, and 3 years 9 months ( 2 years 3 months to 6 years 6 months) for children with moderate learning difficulties. The preschool medical examination revealed fairly minor medical problems: 29 of 81 children referred for specialist opinions were shown to be medically normal, and for only seven of the medically abnormal children was information about their conditions given to their teachers. In Somerset screening the development of all children at predetermined ages has not been very useful.
\end{abstract}

\section{Introduction}

Since 1978 general practitioners in Somerset have done all paediatric preschool surveillance-that is, immunisations and developmental screening.' Until recently the appropriate knowledge and experience that made this possible were derived from previous paediatric experience during their training in hospital and practices and from individual courses that they had chosen to attend. There was no stated policy about the level of training, its aims, or its content. General practitioners and their health visitors were largely left to themselves to formulate what was to be done in each practice. The health authority agreed to pay for two preschool examinations, one at 6 weeks and another before the child started school.

In view of the current interest in the usefulness of developmental screening ${ }^{2}$ we wanted to know how our system in Somerset performed.

Did the regular preschool screening checks identify children with later educational problems?

Did the screening tests pick up treatable medical conditions that would not otherwise have been identified?

2 Camp Road, West Coker, Somerset

David Kearney, MA, chartered psychologist

Correspondence to: Dr Dearlove.

BrMed f 1990;300:1177-80

\section{Methods}

We reviewed the health visitor records (and where necessary the hospital notes or general practitioner's notes) of all 7 year old children in the Yeovil, Crewkerne, and Bridgewater areas who were attending a school during February 1987 and who were born between 1 September 1978 and 31 August 1979. This included any children who received home tuition but were affiliated to a school. The records of 1504 children were reviewed.

We compared the results of two preschool examinations as described elsewhere ${ }^{3}$ with the child's results on stage 1 of the Edinburgh reading test ${ }^{4}$ taken in February of the year in which the child was aged 7 . All schoolchildren in Somerset sit this reading test. It is standardised for age and sex and scored from 70 (very low) to 130 (high) (mean 100). To accommodate schools that were late in sending their results we set the end point for our inquiry at 2 April 1987. The two preschool developmental examinations were the developmental check by a health visitor at 3 to $31 / 2$ years of age and the preschool check done by both general practitioner and health visitor when the child was 4 to $4 \frac{1}{2}$ years old. These two examinations were scored on a pass or fail basis depending upon whether the examiner thought that the child was normal or not.

Many parents see developmental testing as useful for picking up problems that could have an effect on education before the child gets to school. To examine this concept we assumed that developmental screening was a screening test to detect children with special educational needs and looked at the records of all the children who had been statemented (designated as needing special teaching) under the 1981 Education Act and all children who had been seen by an educational psychologist before 2 April 1987 and were receiving help at school (103 children). We then calculated specificities and sensitivities for the preschool medical done by general practitioners and health visitors (1052 children) and for the developmental assessment done by health visitors at age 3 to $31 / 2$ (815 children). We also looked at children from families in social classes IV and V and from single parent or unwaged families (total of 849 children) as a simple way of screening for the likelihood of having special educational needs.

By reviewing the records of all the children who had failed their preschool medical examination and looking at the reasons for their referral to other medical specialties we tried to identify educationally important medical conditions that were picked up solely by screening. We noted whether the medical information had been passed on to the child's teacher. From information obtained from our area's social services office we noted whether the child had been in care.

Because this was a retrospective study using a large number of children only significance levels of $p<0.001$ are reported.
One hundred and nine children did not sit their reading tests. Of these, 37 were withdrawn because their reading was so poor. Thirty of these children were known to have special educational needs before they entered school. Twenty seven of the 30 had either

\section{Results}


failed their preschool medical or not been invited to attend. We could not determine, however, whether the mainstream schools that absented their children from the test did this because the children were truly absent or because of other reasons - for instance, their proportion of non-readers who were classified as withdrawn from the school would then rise, and this could reflect upon the school and its ability to teach children to read.

There was no relation between reading scores and having passed or failed the preschool medical examination (table I). The preschool medical examination was able to identify children who later ran into educational problems but was too insensitive to identify accurately the 103 children we defined as having special needs (table II). Though social class alone as a screening test for later educational problems was both insensitive and non-specific, reading ability was related to a combination of sex and social class (table III), as has been found elsewhere. ${ }^{5}$ Girls from class I and II did significantly better than girls from class IV and V and than boys from class I and II. Part of our large difference could be

TABLE I-Results of preschool medical examination related to reading scores at age 7

\begin{tabular}{|c|c|c|c|c|}
\hline $\begin{array}{l}\text { Preschool medical } \\
\text { examination }\end{array}$ & $\begin{array}{l}\text { No of } \\
\text { children }\end{array}$ & $\begin{array}{l}\text { No of } \\
\text { readers }\end{array}$ & $\begin{array}{l}\text { Mean score on Edinburgh } \\
\text { reading test }{ }^{\star}(95 \% \text { confidence } \\
\text { interval })\end{array}$ & $\begin{array}{l}\%(\mathrm{No}) \text { of } \\
\text { non-readers } \\
\text { at } 7 \text { years }\end{array}$ \\
\hline Passed & 785 & 751 & $105 \cdot 1(103 \cdot 9$ to $106 \cdot 3)$ & $4 \cdot 3(34)$ \\
\hline Failed & 267 & 236 & $102 \cdot 5(100 \cdot 3$ to $104 \cdot 7)$ & $11.6(31) \dagger$ \\
\hline \multicolumn{5}{|l|}{ No result: } \\
\hline Child moved into area & 126 & 116 & $107 \cdot 2(107 \cdot 2$ to $110 \cdot 0)$ & $7 \cdot 9(10)$ \\
\hline Child did not attend & 54 & 51 & $100 \cdot 5(95 \cdot 7$ to $105 \cdot 2)$ & $5 \cdot 6(3)$ \\
\hline Child not invited & 155 & 134 & $104.7(101.7$ to $107 \cdot 7)$ & $13 \cdot 5(21) \ddagger$ \\
\hline Result not known & 177 & 107 & $106.8(103.3$ to 110.0$)$ & $8 \cdot 5(10)$ \\
\hline
\end{tabular}

$t=2 \cdot 12, p<0 \cdot 034$ Between reading score and having passed or failed preschool medical examination. * Standardised for age and sex; scored from 70 to 130 .

+Non-readers who failed their preschool medical compared with those who passed: $\chi^{i}=17 ; \mathrm{df}=1 ; \mathrm{p}<0.001$. $\ddagger$ Non-readers who were invited to a preschool medical examination compared with all those who were medically examined: $\chi^{2}=13 ; \mathrm{df}=2 ; \mathrm{p}<0.001$.

TABLE II-Effectiveness of screening for detecting children with special educational needs

\begin{tabular}{|c|c|c|}
\hline & \multicolumn{2}{|c|}{ Children seen at age 7} \\
\hline & $\begin{array}{l}\text { With special } \\
\text { education needs }\end{array}$ & $\begin{array}{c}\text { No special } \\
\text { education needs }\end{array}$ \\
\hline \multicolumn{3}{|c|}{ Assessed by general practitioner (preschool medical) } \\
\hline $\begin{array}{l}\text { Fail }(n=267) \\
\text { Pass }(n=785) \\
\text { Sensitivity }=56 \% \\
\text { Specificity }=77 \%\end{array}$ & $\begin{array}{l}34 \\
27\end{array}$ & $\begin{array}{l}233 \\
757\end{array}$ \\
\hline \multicolumn{3}{|c|}{ Assessed by health visitor ( 3 year developmental) } \\
\hline $\begin{array}{l}\text { Fail }(n=132) \\
\text { Pass }(n=683) \\
\text { Sensitivity }=45 \% \\
\text { Specificity }=86 \%\end{array}$ & $\begin{array}{l}21 \\
26\end{array}$ & $\begin{array}{l}111 \\
657\end{array}$ \\
\hline \multicolumn{3}{|c|}{ Assessed by both general practitioner and health visitor } \\
\hline $\begin{array}{l}\text { Fail }(n=71) \\
\text { Pass }(n=517) \\
\text { Sensitivity }=50 \% \\
\text { Specificity }=88 \%\end{array}$ & $\begin{array}{l}14 \\
14\end{array}$ & $\begin{array}{r}57 \\
503\end{array}$ \\
\hline \multicolumn{3}{|c|}{ Social class ${ }^{\star}$} \\
\hline $\begin{array}{l}\text { IV, V, unemployed }(n=291) \\
\text { I, II, IIIN, IIIM }(n=558) \\
\text { Sensitivity }=46 \% \\
\text { Specificity }=66 \%\end{array}$ & $\begin{array}{l}25 \\
29\end{array}$ & $\begin{array}{l}266 \\
529\end{array}$ \\
\hline
\end{tabular}

^Registrar General's classification; father's occupation at birth of child taken from health visitor record, hospital notes, or birth record.

TABLE III-Relation of sex, social class, and reading scores

\begin{tabular}{|c|c|c|c|c|}
\hline \multirow[b]{2}{*}{ Social class } & \multicolumn{2}{|r|}{ Boys } & \multicolumn{2}{|r|}{ Girls } \\
\hline & No & $\begin{array}{c}\text { Mean reading score } \\
(95 \% \text { confidence interval })\end{array}$ & No & $\begin{array}{c}\text { Mean reading score } \\
(95 \% \text { confidence interval })\end{array}$ \\
\hline $\begin{array}{l}\text { I, II } \\
\text { IV, V, unemployed }\end{array}$ & $\begin{array}{r}69 \\
134\end{array}$ & $\begin{array}{l}107.0(103.7 \text { to } 110 \cdot 8) \\
100 \cdot 8(97.4 \text { to } 102 \cdot 9)\end{array}$ & $\begin{array}{r}62 \\
135\end{array}$ & $\begin{array}{c}116.0(113.3 \text { to } 119 \cdot 2)^{\star} \dagger \\
99 \cdot 2(95 \cdot 5 \text { to } 101.6)\end{array}$ \\
\hline
\end{tabular}

* Girls from social class I and II compared with girls from social class IV and V: $t=8 \cdot 36, \mathrm{p}<0 \cdot 001$

tGirls from social class I and II compared with boys from social class I and II: $t=3 \cdot 78, p<0 \cdot 001$. explained by postulating that the Edinburgh reading test's standardisation is inaccurate for girls from class I and II or simply that these girls are smarter than the boys.

Of the 267 children who failed their preschool medical examination, 159 failed because a new problem was discovered on this examination. Some children had more than one abnormality. Table IV looks at the results and outcomes. Of 159 children with 171 problems, 81 children were referred to medical specialists. Of these 81,29 were said to be normal after their first hospital visit and a further 29 had been discharged from specialist care by the end of our study. Medical information was passed on to the teachers of only seven of the 159 children who failed their medical examination.

Only three children failed the developmental part of their preschool medical examination. One of these children was of very short stature, which caused her to be referred to a paediatric clinic, where her idiopathic hypercalcaemia was diagnosed. The two other children remain in mainstream schooling but need additional help.

Twenty two of the 23 children in schools specifically for children with severe and moderate learning difficulties were identified independently of any of their developmental screening. The mean age at which intervention started for the seven children with severe learning difficulties was 1 year 5 months (range 2 months to 3 years). Three had been recognised by health visitors, three within the hospital outpatient medical service, and one by the local opportunity group leader. The 16 children with moderate learning disorders were recognised by the age of 3 years 9 months (range 2 years 3 months to 6 years 6 months). Six were identified by the teacher of the nursery, five by the health visitor, two by the hospital outpatient medical service, one by the child's mother, one by a local senior clinical medical officer, and one by the playgroup leader.

We looked at the ages at which intervention started because the expected route for children with neurodevelopmental problems is screening followed by a detailed assessment and then intervention. What seems to have happened in the group of 22 children is that the problem was recognised and intervention started; a detailed assessment was performed almost as an adjunct. That is not to say that the children missed out on assessments. All except one child had more than one assessment, but the initiation of therapy, and its content, did not depend on a detailed assessment of the child.

Despite being identified early and receiving medical and educational attention, all the children originally placed in schools for children with severe and moderate learning difficulties stayed in their original placements. Six out of the 80 children identified later and placed in mainstream schooling were in schools for children with moderate learning difficulties by the end of the study.

\section{Discussion}

Our results suggest that the medical usefulness of developmental screening tests by health visitors and general practitioners for identifying educationally important medical problems is small. Also, most children with special educational needs seem to be identified independently of their screening tests. As well, developmental screening in Somerset is an insensitive method for detecting children with special needs.

This retrospective cohort study of 1504 children shows that our system of regular developmental checks did not contribute significantly to the detection of later educational difficulties. Assuming that the results of 


\begin{tabular}{|c|c|c|c|c|c|c|c|c|}
\hline & \multirow{2}{*}{$\begin{array}{c}\text { New } \\
\text { problems }\end{array}$} & \multirow[b]{2}{*}{ Referrals } & \multirow[b]{2}{*}{ Diagnosis } & \multirow[b]{2}{*}{ Treatment } & \multicolumn{4}{|c|}{ Outcome } \\
\hline & & & & & Normal & Unknown & Discharged & Followed up \\
\hline \multirow[t]{3}{*}{ Vision } & 59 & 30 & Hypermetropia $(n=1)$ & Glasses & & & 1 & \\
\hline & & & Strabismus $(n=8)$ & Glasses & 8 & & & \\
\hline & & & Myopia $(\mathrm{n}=21)$ & Glasses & 12 & 5 & 4 & \\
\hline \multirow[t]{5}{*}{ Hearing } & 50 & 24 & Reduced hearing & & 1 & 2 & & \\
\hline & Jo & 27 & Referred to ENT $(n=15)$ & Grommets & 1 & & 9 & 1 \\
\hline & & & & Decongestant & & & 1 & \\
\hline & & & & Nose cauterised & & & 1 & \\
\hline & & & Referred to audiology $(n=9)$ & & & & 7 & 2 \\
\hline \multirow[t]{6}{*}{ Speech } & 24 & 13 & Lisp & & 3 & & & \\
\hline & & & Poor articulation & & & & 2 & \\
\hline & & & Speech delay & & & & 2 & \\
\hline & & & Referred to ENT & Operations and speech therapy & & & & 4 \\
\hline & & & Husky voice & & 1 & & & \\
\hline & & & Language delay & & & & & 1 \\
\hline \multirow[t]{3}{*}{ Development } & 8 & 3 & Global delay: & & & & & \\
\hline & & & Referred to paediatrician & Special schooling & & & & 2 \\
\hline & & & Referred to opportunity group & Extra help in school & & & & 1 \\
\hline \multirow[t]{7}{*}{ Physical } & 30 & 11 & Systolic heart murmur & & & & 1 & 2 \\
\hline & & & Undescended testes & & 2 & & & \\
\hline & & & Umbilical hernia & & 1 & & & \\
\hline & & & Tight prepuce & & 1 & & & \\
\hline & & & "Chesty" & For asthma & & & & 2 \\
\hline & & & Small stature & For idiopathic hypocalcaemia & & & & 1 \\
\hline & & & Flat feet & & & & 1 & \\
\hline
\end{tabular}

preschool developmental screening should be related to the child's later educational achievement, why did we do so poorly?

Firstly, developmental screening at predetermined ages may be unrealistic. Parents go to general practitioners at irregular intervals ${ }^{5}$; most of our severely handicapped children with special educational needs were identified when someone was worried, and any developmental testing then confirmed developmental delay. This use of a formalised assessment of development as a check rather than as a screen is similar to the practice of primary care paediatricians elsewhere. ${ }^{7}$ Our survey of the 59 general practitioners caring for the children in this study supports this view: 36 of the 37 who replied thought that developmental screening revealed little that they did not already know about the child.

Secondly, our local developmental screening programme may set itself unrealistic goals. Screening for the conditions causing mental handicap that are curable, such as phenylketonuria or hypothyroidism, fulfils the World Health Organisation criteria for a screening test, ${ }^{8}$ but many other conditions causing mental handicap are incurable. Probably because of their rather non-specific targets developmental screening tests are often poorly validated, ${ }^{9}$ and this is compounded by the fact that most of the health visitors involved with these children used a mixture of developmental tests. So our results are hardly a surprise. To overcome this problem Somerset has started using the Denver developmental screening test as a screening instrument for all preschool children. This test is well validated ${ }^{10}$ and may lead to useful comparisons with the present system when Somerset education department changes to standard attainment targets in 1991 or 1992. General practitioners looking for measurable assessments of quality" within their own screening programme would obviously not have access to these sorts of external outcome measurements, and hence general practitioners and parents will not be able to judge how useful a particular developmental screening programme actually is.

Thirdly, we found that 22 out of 23 of the statemented children with learning difficulties were picked up independently of the screening programme. This implies that our screening procedures were largely peripheral to identifying children with learning difficulties. On the other hand, though only 22 children of the 103 with special educational needs had been identified before school entry, these were $96 \%$ of the most handicapped children-that is, those in special schools. This emphasises the value of secondary identification pathways such as playgroups, opportunity groups, nurseries, parents, and health visitors.

Our findings and other evidence ${ }^{12-15}$ suggest that there may be more effective methods of looking at preschool children than with the increasing number of medically related screening tests that the government proposes $^{16}$ - for example, asking parents, ${ }^{178}$ opportunistically in the general practitioner's surgery, ${ }^{19}$ or through questionnaires. ${ }^{2021}$ It may be worth while to review only certain groups of children. Whichever method is used, being able to assess it is essential. ${ }^{22}$ The short term difficulty with screening and assessment is that the proposed general practitioner contract contains no details about the frequency, content, or even the aims of preschool surveillance. Rather, it will be the responsibility of the district health authority to define the content, training, auditing, and accreditation of the general practitioners carrying out childhood surveillance. ${ }^{23}$ Somerset Health Authority can effectively audit immunisation programmes by general practitioners and is currently looking at its preschool surveillance programme from the points of view of both health visitors and general practitioners. The other key conditions within the proposed schedule seem to show that there is a realistic move away from trying to define a child's developmental progress towards an attempt to audit measurable items, such as reviews of biochemical screening.

We thank Ms Heather Trott and Ms Ruth James for considerable administrative help; Dr Paul Ewings and Ms Jenny Lythell for statistical advice, help, and encouragement; Ms Karen Jefferies and Ms Caroline Wright for secretarial help; and the East Somerset Community Services Unit, Somerset Health Authority, and the Balidon Research Fund for financially supporting this study.

1 Bowie D, Parry Jones A. Court come true - for better or for worse? Br Med f 1984;299:1322-4.

Hall DMB (ed). Health for all children. Oxford: Oxford Medical Publishers, 1989.

3 Somerset Health Authority. Child health surveillance handbook. Taunton: Somerset Health Authority (in press)

4 Carroll DJ. Edinburgh reading tests - stage 1. London: Hodder and Stoughton, 1977

5 Tizzard B, Blatchford P, Burke J, Farqutiar C, Plewis I. Young children at school in the inner city. London: Laurence Erlbaum, 1988.

6 Mayall B. Keeping children healthy. London: Allen and Unwin, 1986

7 Smith R. The use of developmental screening tests by primary care paediatricians. I Pediatr 1978;93:524-7.

8 Wilson J, Jungner G. Principles and practice of screening for disease. Geneva: World Health Organisation, 1968. (Public Health Papers No 34.)

9 Frankenburg W, Camp B. Paediatric screening tests. Springfield, Illinois: Charles C Thomas, 1975.

10 Frankenburg WK, Camp BW, Van Natta PA. Validity of the Denver screening test. Child Dev 1971:42:475-85.

Hed


11 Pendelton D, Schofield T, Marinker M. In pursutt of qualitv. London: Royal College of General Practitioners, 1986

2 Ingram RM Amblyopia. Br Med 1989,298:204

13 Yule W, Rutter M. Language development and disorders. Oxford: Blackwell Scientific, 1987:189-93. Clinics in Development Medicine 101/102.

14 Bishop D. Otitis media and developmental language disorder: a reply to Gordon. $f$ ('hild Pswchol Psychiatry 1988;29:265.

15 Silva PA, Williams SM, McGee R. A longitudinal study of children with developmental language delay at age 3 . Later intelligence, reading and hehavioural problems. Dev Med Child Neurol 1987;29:630-40.

6 Secretaries of State for Health, Wales, Northern Ireland, and Scotland. Working for Patients. London: HMSO, 1989. (Cmnd 555.

17 Linde DB, Engelhartdt KF. What do parents know about infant development. Paediatric Nursing 1979;1:33-6.

18 Knobloch H, Stevens F, Malone A, Ellison P, Risenberg H. The validity of parental reporting of infants' development. Paediatrics 1979;63:872-8.
19 Williams PR. Opportunistic surveillance of children. $7 \mathrm{R}$ Coll (ien Pract 1985:35:77-9.

20 Frankenburg W'K, Fandal AW, Thornton SM. Revision of the Denver prescreening developmental questionnaire. I Pediatr 1987;10:653-757.

21 Sonnander K. Early identification of developmental delayed children: reliability, validity, and predictive value of a parental assessment instrument. Uppsala: University of Uppsala, 1987. (Dissertation.)

22 Drillien C, Drummond MB. Development screening and the child with speciol needs. London: Heinemann Medical, 1983. (Clinics in Developmental Medicine 86.)

23 Periera Gray D, Lloyd J. Guidelines for the training and accreditation of general practitioners in child health surveillance. London: Royal College of General Practitioners and British Paediatric Association, 1989.

(Accepted 7 February 1990)

\title{
Screening in Practice
}

\section{Screening and surveillance of school aged children}

\author{
John W Tuke
}

Three progressive moves seem to be taking place. Firstly, the white paper Promoting Better Health, through its encouragement of disease prevention and health promotion, accepts that much morbidity and premature mortality is behaviourally determined and therefore preventable. Secondly, the wish to move towards a true concept of primary health care in Europe, not a provision normally contained within traditional medical services, extends the role of the family doctor into that of an observer of patients throughout their lifespan.' This is one definition of surveillance: "The ongoing supervision of the preventive care of a practice population" (C R Hart, personal communication). Thirdly, individuals and their families are the nearest and often the best observers of deviation from normality, and as they are usually correct this latent resource should be exploited. ${ }^{2-6}$

\section{Who needs observation?}

Children from 5 years to school leaving, because they are developing and dependent on the ingredients of their environment, are especially vulnerable when some physical, emotional, or intellectual problem intrudes to interfere with social and educational progress. Environment, nutrition, and immunisation have radically changed the epidemiology of childhood; physical illness has been largely replaced by problems of communication, behaviour, and social inadequacy. If failure to achieve, school difficulties, drug and alcohol abuse, smoking, and adolescent problems (box) are to be predicted and prevented an accessible and responsive facility is required to give timely and effective help..$^{7.10}$ This means listening to and taking seriously the anxieties of children, parents, and teachers and is the basis of the flexible and reactive model of school health services pioneered in Northumberland. ${ }^{11}$ Initial assessment can be made by someone with an understanding of child development, the early indicators of dysfunction, and the available facilities for their management. Surely this includes the general practitioner.

West Suffolk Health

Authority,

Bury St Edmunds, IP33 1YJ

John W Tuke, MRCGP, consultant in public health medicine

Br.Med f 1990;300:1180-2

\begin{tabular}{|c|c|c|}
\hline \multicolumn{3}{|c|}{ What can we prevent or modify? } \\
\hline Preschool indicators & At school & Later \\
\hline Undervalued & Poor self esteem & $\begin{array}{l}\text { Difficulties in } \\
\text { relationships }\end{array}$ \\
\hline $\begin{array}{l}\text { Slow development } \\
\text { of speech or } \\
\text { language }\end{array}$ & Underachievement & $\begin{array}{l}\text { Poor employment } \\
\text { prospects }\end{array}$ \\
\hline Poverty & Solvent abuse & Drug misuse \\
\hline $\begin{array}{l}\text { Emotional or } \\
\text { behavioural } \\
\text { difficulties }\end{array}$ & & $\begin{array}{l}\text { Alcohol misuse (drink } \\
\text { driving; accidents) }\end{array}$ \\
\hline \multirow{3}{*}{$\begin{array}{l}\text { Family problems } \\
\text { Child abuse }\end{array}$} & $\begin{array}{l}\text { Behaviour problems } \\
\text { School problems }\end{array}$ & \\
\hline & & $\begin{array}{l}\text { Repeat in next } \\
\text { generation }\end{array}$ \\
\hline & Smoking & Smoking \\
\hline
\end{tabular}

the 1981 Education Act, is the early identification of children with special needs. This is not restricted to formal education. It is intended to ensure that from the age of 2 years children with disabilities or handicaps that might affect their education are formally assessed and a statement prepared indicating the help required. The act relates to the $20 \%$ of children who at some time during their schooling will require special assistance. ${ }^{12}$ Such children must be reviewed at least annually, and it is the duty of the local authority to coordinate this process and to include medical advice.

\section{Particular problems}

HEARING

The child with bilateral perceptive or sensorineural hearing. loss will have been identified before school entry. The average age for first diagnosis has been reduced from $3 \frac{1}{2}$ years in 1978 to 11 months in 1988 , which, although not ideal, should allow most of these children to achieve acceptable speech, language, literacy, and social expectations.

A much more common problem in the school years is conductive hearing loss due to middle ear disease, especially otitis media with effusion-"glue ear." Repeated screening of school children has not been shown to affect long term outcome of this impairment, and it is doubtful if this should be continued. . $^{13-15}$ Evidence for the long term effectiveness of available treatment is hard to find, and complications of treatment are not unknown..$^{14 \mathrm{1} a}$ This does not imply that it is unhelpful to know of the existence of partial 